\title{
Comparison of coherent optical transmission systems performance by DP-QAM levels
}

\author{
Abdul Gafur ${ }^{1}$, M. S. Islam ${ }^{2}$, Syed Zahidur Rashid ${ }^{3}$ \\ 1,2 Department of Physics, Jahangirnagar University, Bangladesh \\ ${ }^{1,3}$ Department of Electronic and Telecommunications Engineering, \\ International Islamic University Chittagong, Bangladesh
}

\begin{tabular}{l} 
Article Info \\
\hline Article history: \\
Received Sep 25, 2019 \\
Revised Nov 5, 2019 \\
Accepted Nov 25, 2019 \\
\hline Keywords: \\
BER \\
DP-QAM \\
EVM \\
OSNR
\end{tabular}

\begin{abstract}
In this paper, we investigated the Coherent Optical Transmission System (COTS) performance for multiple types of DP-QAM levels considering various $\mathrm{CW}$ laser input power. We compared the performance of COTS for $100 \mathrm{~Gb} / \mathrm{s}$ with DP-32QAM, DP-64QAM and DP-128QAM respectively. We also inspected the relationship among Optical Signal to Noise Ratio (OSNR), Error Vector Magnitude (EVM) and Bit Error Rate (BER) which are found in accordance for both simulation curves and constellation diagrams. Results are obtained by experiments with DP-32QAM, DP64QAM and DP-128QAM modulations techniques at symbol rate of 10 Gsymbol/s, $8.33 \mathrm{Gsymbol} / \mathrm{s}$ and $7.142 \mathrm{Gsymbol} / \mathrm{s}$ respectively. This work is completely based on simulation in Optisystem simulation setup.
\end{abstract}

Copyright $\left({ }_{0} 2020\right.$ Institute of Advanced Engineering and Science. All rights reserved.

\section{Corresponding Author:}

Abdul Gafur,

Department of Electronic and Telecommunication Engineering,

International Islamic University Chittagong,

Kumira, Chittagong-4318, Bangladesh.

Email: agafur_cox@yahoo.com

\section{INTRODUCTION}

At present, realizing higher bit rates, capacity and lower cost per bit for long haul coherent optical transmission systems (COTS) are leading research interests [1, 2]. It is well known that up to $10 \mathrm{~Gb} / \mathrm{s}$ On-Off Keying (OOK) with association of either return-to-zero (RZ) or non-return-to-zero (NRZ) modulation technique works very well from transceiver point of view. But for higher data rates, these modulation formats also show some drawbacks such as spectral inefficiency along with linear and nonlinear effects of optical fiber [3]. For COTS, the parameters upon which efficiency relies on are capacity, optical link distance, spectral efficiency, bandwidth of the channel and optical system design [4]. Consequently, advanced modulation formats are extensively applied for meeting continuously growing demands in COTS [5-7]. Moreover COTS has the merits of anti-polarization dispersion and better sensitivity in the receiver which is not the case for direct detection modulation technique. Also COTS is compatible with Multi level modulation format and has better spectral efficiency. Due to these advantages, COTS is employed in DWDM systems [8].

Besides QAM has the capability to obtain very higher spectral efficiency over optical frequency bands [9]. Thus DP-QAM is one of the potential modulation candidates for COTS [10]. DP-QAM modulation levels are widely employed for satisfying increasing demands of higher spectral efficiency as well as higher capacity whereas it also shields against linear and nonlinear affects in optical fibers [11]. This modulation format is an operator for both the amplitude and phase alteration along with dual polarization in the COTS [12]. Furthermore Dual polarization QAM provides higher bits/symbol rate which ultimately leads to efficient utilization of the frequency spectrum [13]. On the contrary, more inspection and 
safe guarding are must for Dual polarization QAM [14]. In situations where optical channels are impaired by amplified spontaneous emission (ASE) noises, the error vector magnitude (EVM) and the optical signal to noise ratio (OSNR) play a pivotal role in measuring the performance of those optical channels [2, 5]. By the same token, it is very much important to portray optical I-Q transmitters [15]. Still now, the interaction of BER and OSNR with respect to EVM is not well ascertained in COTS [16]. Moreover, EVM is better metric than BER when symbol sequences are unknown. Thereby association between EVM and BER are highly momentous for COTS [15]. In this paper the effect of nonlinear distortion on DP-QAM based COTS was analyzed in Optisystem software environment. In case of QAM, information encoding is done on amplitude and phase which required very sophisticated analysis and quantization technique to measure the efficiency of COTS [17]. EVM and OSNR are widely applied parameters for evaluating the performance of COTS where the optical channels are adversely affected by ASE noise and I-Q transmitters [17].

With the help of EVM we can calculate the deviation of actual received data from the expected value of demodulated data [18]. But signal-to-noise ratio (SNR), EVM and BER originally derived wireless digital communications which are not compatible with optical communications systems [5]. Proper algorithm of COTS is necessary for accurately validating the interdependency between EVM and BER [17, 19]. The prime parameters that were analyzed here are Input transmitting power, propagation optical length, EVM, BER and OSNR. Proper investigation of EVM is an inevitable which necessitates the derivation of an analytical closed form expression for EVM [20]. In addition to that simulated outputs of the constellation diagrams for $\mathrm{x}$ polarization and y polarization were found in accordance to our findings. We derived a novel expression presenting the relationships among EVM, OSNR and BER for the designed transmitter receiver of the COTS. Then we designed the algorithm for simulation flow representing the complete simulated COTS architecture. We presented our simulation results along with comparison table containing the existing works and thereby validation of our findings from the simulated COTS is shown. This paper is decorated as follows: In Section 1, in the introduction part we provided background with literature review, the problem statement and our novel analytical expression where the interaction among BER, OSNR and EVM are presented mathematically. In Section 2, analytical analysis of the work is presented. In Section 3 describes the simulation layout of the systems. In Section 4, we incorporated the results and findings. Conclusion of the paper and future directions are provided in Section 5.

\section{ANALYTICAL ANALYSIS}

EVM is the measurement of the difference between reference signal and received signal. Consequently, magnitude error, vector error and phase error produced between the transmitted symbols and received symbols in COTS. The mathematical expression $[3,21]$ to determine the EVM of the COTS is as follows

$$
E V M=\frac{\sqrt{\frac{1}{N} \sum_{n=1}^{N}\left|S_{t}(n)-S_{r}(n)\right|^{2}}}{D}
$$

where, $N$ is the total number of transmitted bits, $S_{t}(n)$ is the function of reference transmitted bits, $S_{r}(n)$ is the function of received bits in the systems and $D$ is the operator which maximize the magnitude $\left(R_{\max }\right)$ or either maximize the normalized or average bit power $\left(P_{0}\right)$ for all transmitted bits for the preferred modulation levels. As a result, EVM is inversely proportional to the signal to noise ratio (SNR) [22]. OSNR is equal to the multiplication of SNR with bit rate $\left(R_{s}\right)$ when the result of multiplication is divided by the reference optical bandwidth $\left(B_{r e f}\right)$ [2]. The following formula [3, 16, 23, 24] is to measure the bit error rate for the EVM which is expressed below in the (2)

$$
B E R \approx \frac{\left(1-L^{-1}\right)}{\log _{2} L} \operatorname{erfc}\left[k^{-1} \sqrt{\frac{3 \log _{2} L}{\left(L^{2}-1\right)} \frac{\sqrt{2}(O S N R)\left(B_{r e f}\right)}{R_{s} \log _{2} M}}\right]
$$

In (2), $R_{S}$ represents the bit rate. $B_{r e f}$ is the reference optical bandwidth. $L$ and $M$ are the bit levels and constellation points number of the desired modulation levels respectively. In this way, for DP-32QAM, DP-64QAM and DP-128QAM formats, $L$ and $M$ produce the 5, 6, 7 bits and 32, 64 and 128 constellation points respectively. OSNR is the optical signal to noise ratio. $k$ is the ratio of received and typical constellation points in COTS for DP-QAM levels. 


\section{SIMULATION LAYOUT}

Figures 1, 2, 3 and Figures 4(a), 4(b) represent [3, 11, 25, 26] the block diagram of COTS, algorithm of simulation flow for DP-QAM based COTS, architecture test bed of COTS, layout of coherent QAM square DP transmitter and receiver of COTS respectively. The system consists of coherent QAM square DP transmitter; optical link and coherent QAM square DP Receiver. The optical link section consists of optical fiber and EDFA. Data rate of $100 \mathrm{~Gb} / \mathrm{s}$ is considered to simulate the test bed of COTS with DP-QAM in Optisystem optical simulation software tool. In this scenario, coherent QAM square DP transmitter transmits at the wavelength of $193.1 \mathrm{THz}$ for various DP-QAM levels. Then the transmitted signal is separated in $\mathrm{X}$ and $\mathrm{Y}$ components. Consequently, the outputs go through the I-Q modulator and thereby yield DP-QAM signals. Now the modulating DP-QAM signals passed through the optical amplifier. The amplified signal passed through the optical link with $80 \mathrm{~km}$ span length considering single mode fiber (SMF).

To compensate the fiber attenuation and nonlinearities of the SMF, the optical amplifier used in the link. At the receiver section, coherent QAM square DP receiver is employed to detect the optical signal. In receiver module PBS (Polarization Beam splitter) creates two reciprocally polarized signals. For the detection of four optical fields there are four photodiodes are used to convert the optical signal to electrical signal. After that the electrical signal is passed through the analog to digital converter (ADC) to get the digital signals. Eventually DSP processor module used in the simulation for minimization of frequency and phase differences that occur in the COTS which is then go through the threshold based circuitry. Afterward bit error rate test tool is used to assess the BER performance of COTS for DP-QAM levels.

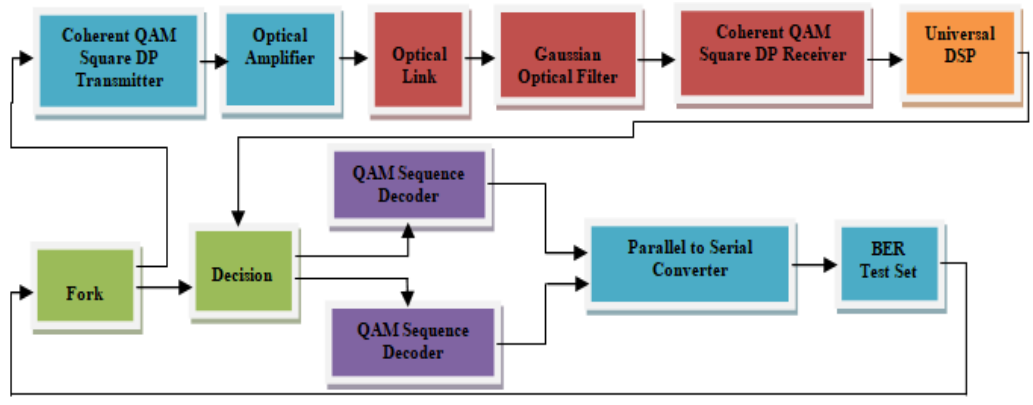

Figure 1. Schematic block diagram of simulation setup for COTS

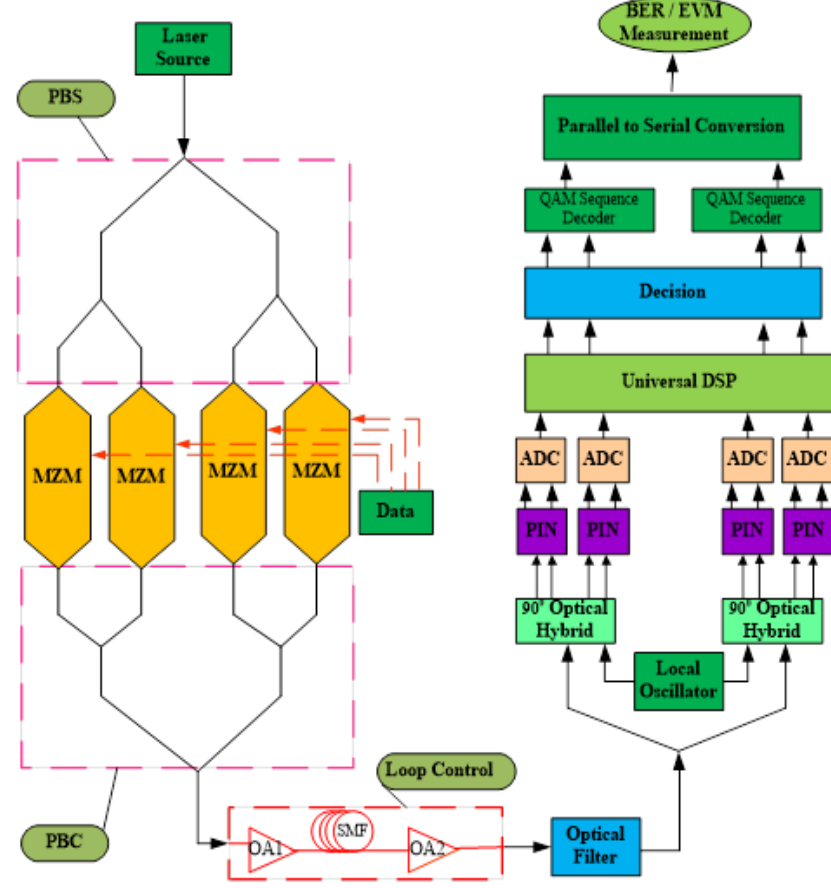

Figure 2. Algorithm of simulation flow for DP-QAM based COTS, where PBS-polarization beam splitter, MZM- mach-zehnder modulator, OA- optical amplifier, PIN-p-i-n photodiode 


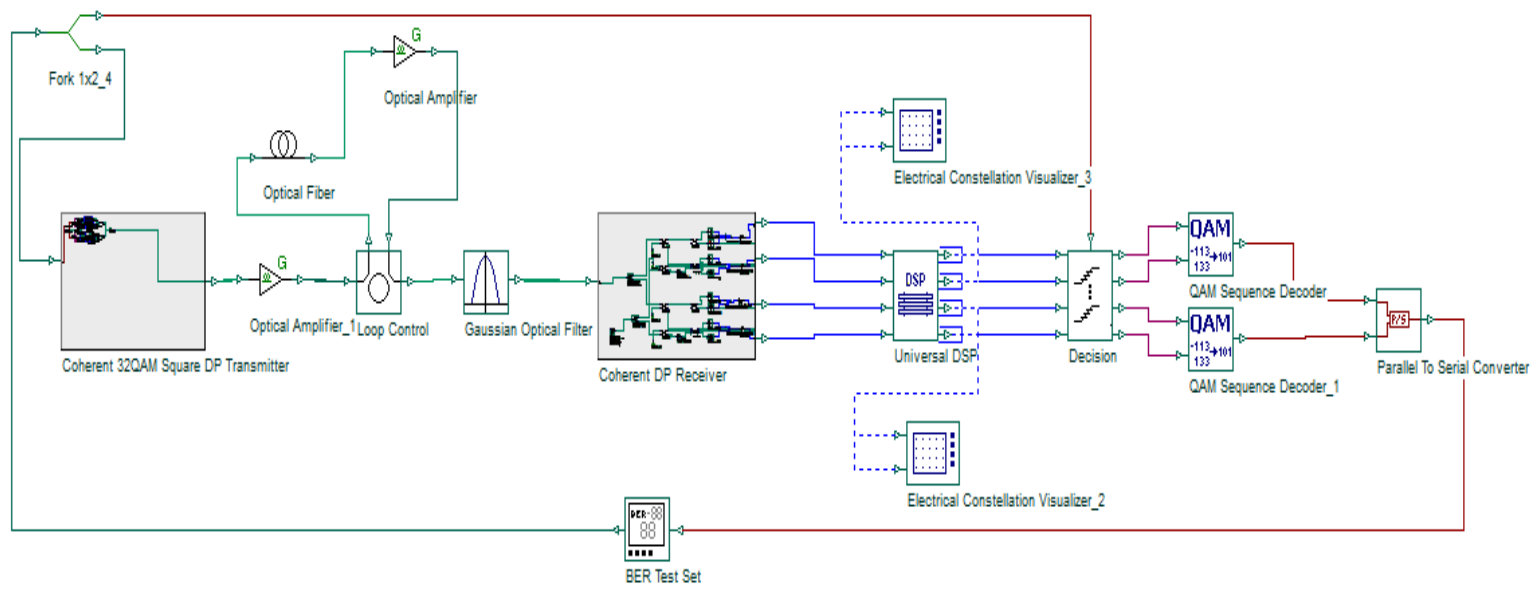

Figure 3. Architecture of test bed COTS

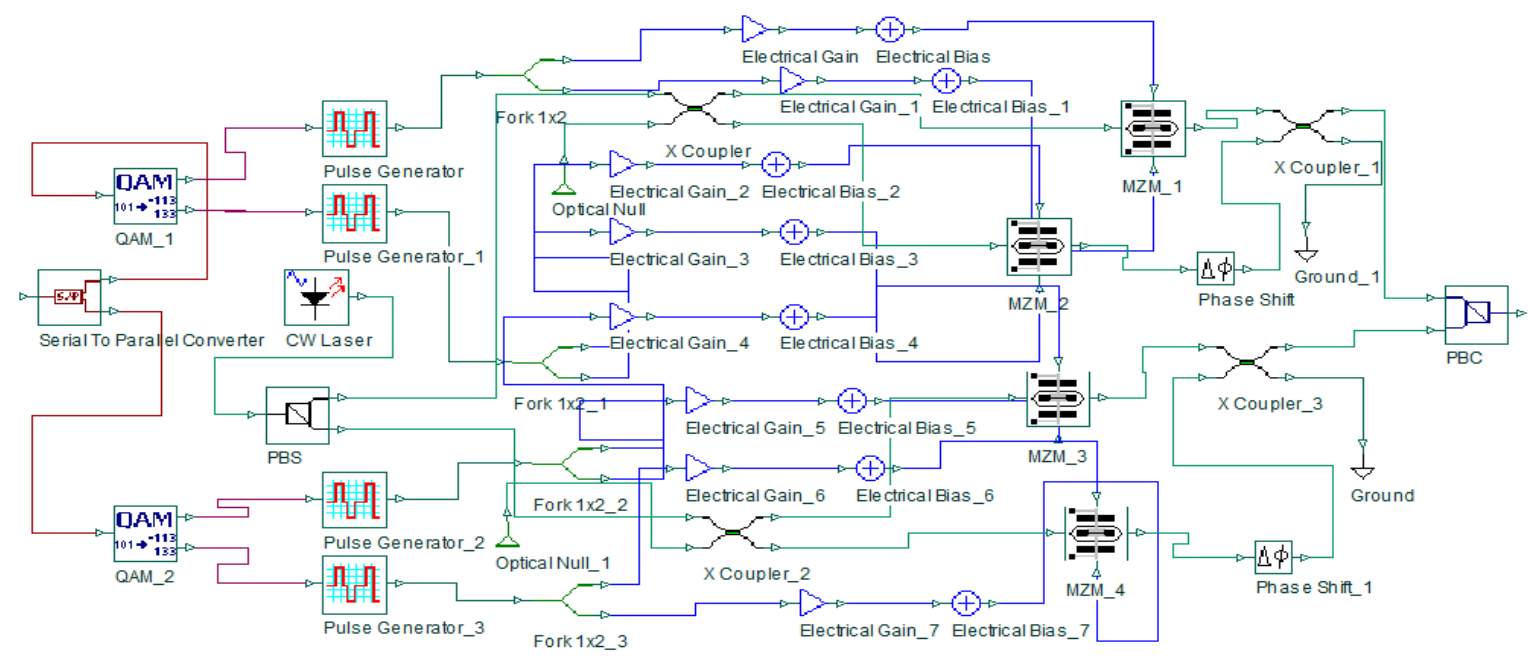

(a)

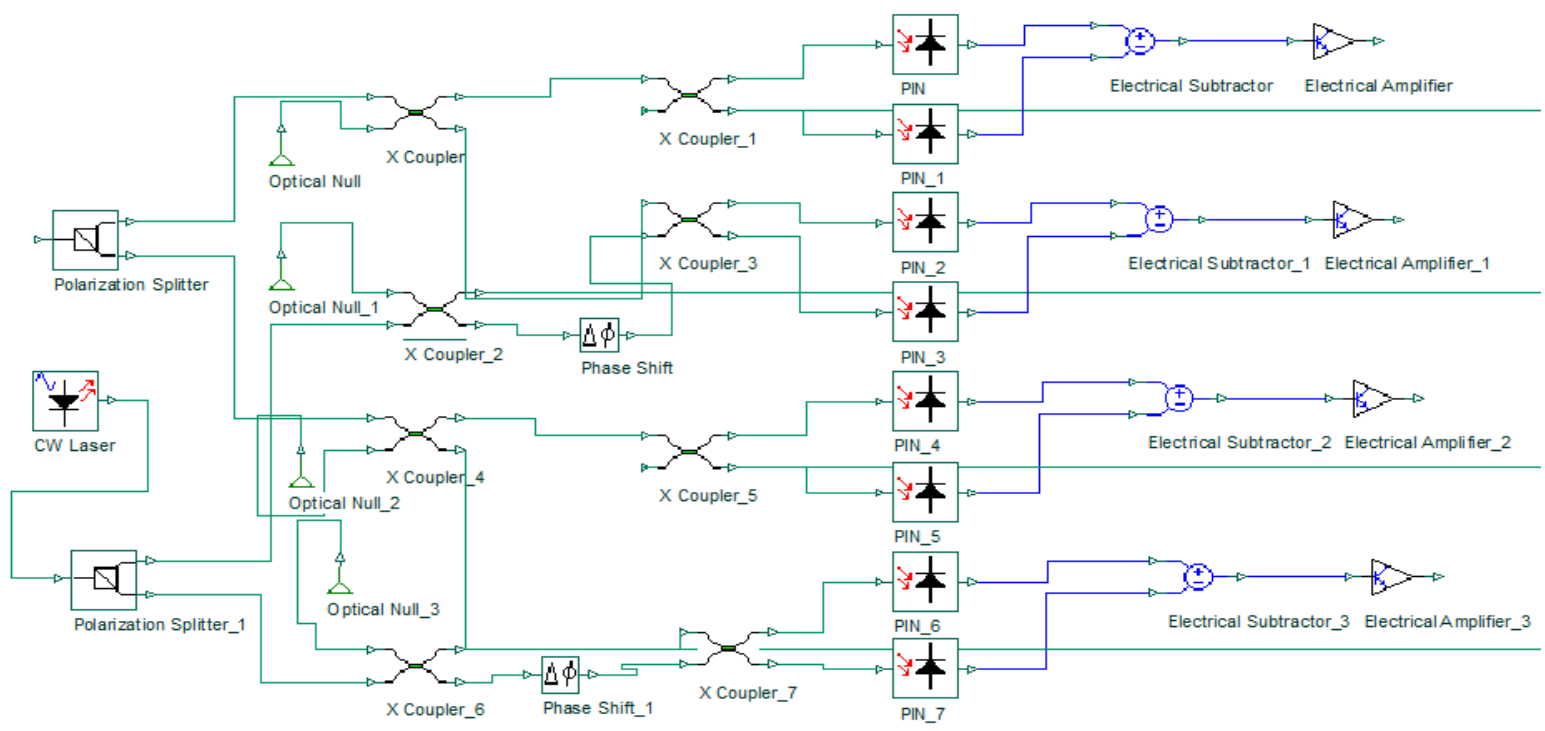

Figure 4. (a) Optisystem layout of coherent QAM square DP transmitter,

(b) Optisystem layout of coherent QAM square DP receiver 


\section{RESULTS}

Global parameters for the system are data rate of $100 \mathrm{~Gb} / \mathrm{s}$, dual polarization, square constellation types, 65536 number of samples which are used to simulate the COTS. As a result the symbol rate for DP-32QAM, DP-64QAM and DP-128QAM are $10 \mathrm{Gsymbol} / \mathrm{s}, 8.33 \mathrm{Gsymbol} / \mathrm{s}$ and 7.142 Gsymbol/s respectively. The operating channel wave length is $193.1 \mathrm{THz}$. The operating input power for CW Laser is $-20 \mathrm{dBm}$ to $5 \mathrm{dBm}$. The operating Optical Signal to Noise Ratio (OSNR) is 12 to $30 \mathrm{~dB}$. The fiber link is of $80 \mathrm{~km}$ span length. The fiber attenuation is $0.2 \mathrm{~dB} / \mathrm{km}$. The fiber dispersion coefficient is $16 \mathrm{ps} / \mathrm{nm}-\mathrm{km}$. The gain of EDFA is $16 \mathrm{~dB}$ and the noise figure is $4 \mathrm{~dB}$. Fiber Nonlinearities is $26 \mathrm{e}^{-021} \mathrm{~m}^{2} / \mathrm{w}$ and fiber effective area is $80 \mathrm{e}^{-012}$. Following the systematic procedure and test bed of COTS, we have found the following results. Figure 5 represents the optical modulating signal displays in Optical Spectrum Analyser (OSA) before sending through the optical link. After the DP-QAM the input message signal as shown in Figure 5, is transmitted through the optical Channel. In the receiver module the downlink receiver is used to demodulate the received signal which was transmitted through the optical channel. And it is splitted in electrical form to the in channel and quadrature channel parts.

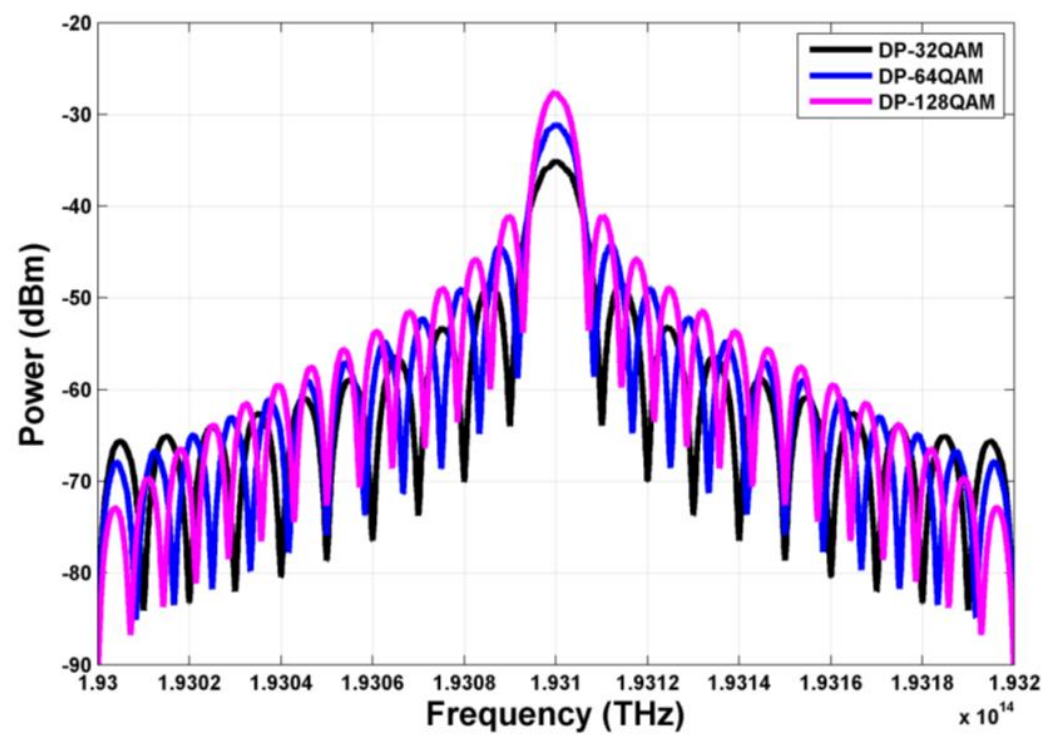

Figure 5. Input power versus frequency of CW laser

Figure 6 represents the comparison for input power $(\mathrm{dBm})$ for DP-QAM level schemes in terms of EVM (\%). In Figure 6, it is found that the propagation efficiency is examined by changing the $\mathrm{CW}$ input power to observe the corresponding impact of $\mathrm{CW}$ input power on Error vector magnitude(\%) for the distance of back to back (B2B), $80 \mathrm{~km}$ and $400 \mathrm{~km}$ after reimbursement for the dispersion effect of the optical propagation system. In this setup the EVM is calculated in case of DP-32QAM, DP-64QAM, and DP-128QAM. The setup reveals that EVM figure for various modulation techniques has an inclination to down fall behavior against $\mathrm{CW}$ input power. At $-9 \mathrm{dBm}$, there is an unusual phenomenon that the linearity of the output graphs tends to more down wards. At input power $-9 \mathrm{dBm}, \mathrm{DP}-128 \mathrm{QAM}$ shows the EVM of 9.5\%, 9.6\%, and $10.7 \%$ where DP-64QAM exhibits the EVM of $12.24 \%, 13.3 \%$ and $15.1 \%$ and lastly DP-32QAM provides the EVM of $17.45 \%, 19.23 \%$ and $22.34 \%$ for back to back, 1 span and 5 spans respectively.

Figure 7 exposes the behavior of EVM with respect to propagation length at $\mathrm{CW}$ input powers of $0 \mathrm{dBm}$ and $5 \mathrm{dBm}$ in case of DP-32QAM, DP-64QAM, and DP-128QAM. It is observed from the figure that EVM increases with the increment of the distance. At $100 \mathrm{~km}$ to $220 \mathrm{~km}$, among all of the modulation formats considered here in this setup, $0 \mathrm{dBm}$ provides higher EVM as compared to $5 \mathrm{dBm}$. At $220 \mathrm{~km}$ to 600 $\mathrm{km}$, DP-64QAM shows higher EVM for $5 \mathrm{dBm}$ as compared to $0 \mathrm{dBm}$. On the other hand, DP-32QAM and DP-128QAM both provides higher EVM in case of $0 \mathrm{dBm}$ as compared to $5 \mathrm{dBm}$. And at 600 to $1200 \mathrm{~km}$ point it reaches to the pick point in case of input power of $0 \mathrm{dBm}$ and $5 \mathrm{dBm}$. It is interesting to observe that DP-32QAM, DP-64QAM, both shows almost similar behavioral patterns for $0 \mathrm{dBm}$ and $5 \mathrm{dBm}$. On the contrary, DP-128QAM provides more \%EVM for $5 \mathrm{dBm}$ input power where it shows lesser EVM for $0 \mathrm{dBm}$. 


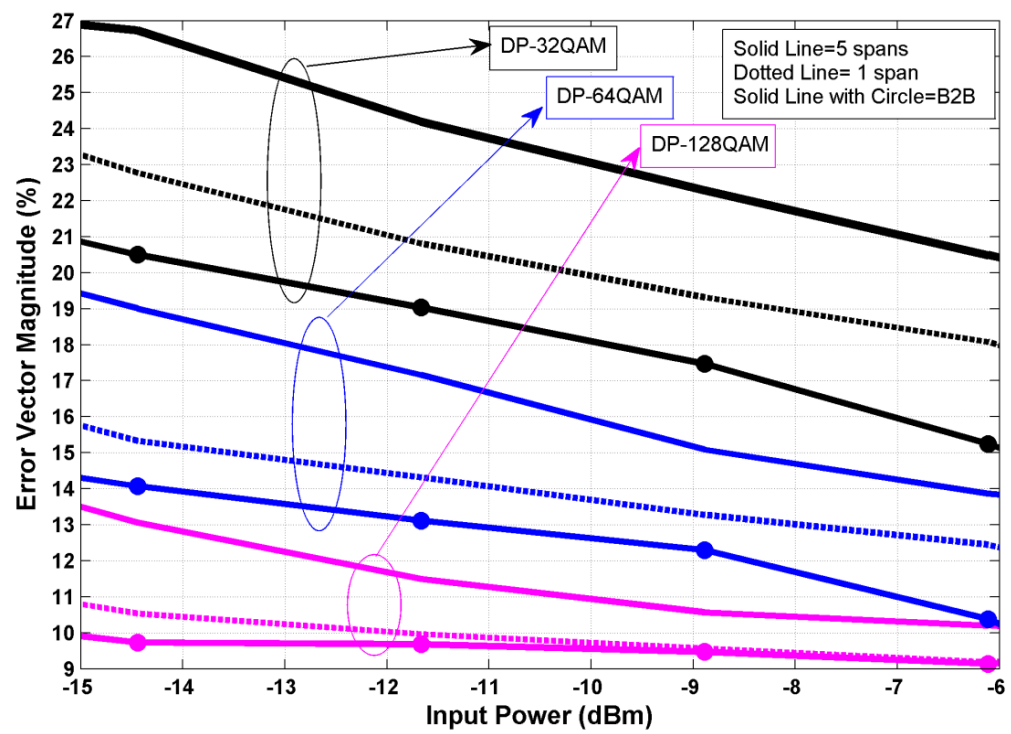

Figure 6. Performance comparison for input power ( $\mathrm{dBm}$ ) for DP-QAM level schemes in terms of EVM (\%)

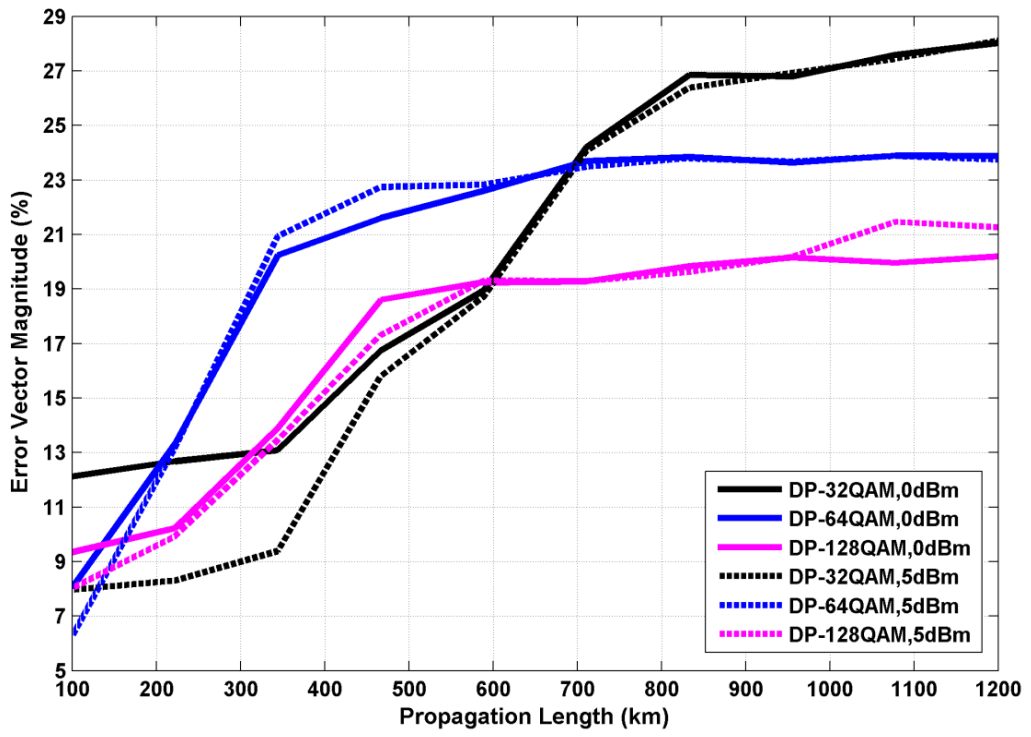

Figure 7. Propagation length $(\mathrm{km})$ versus error vector magnitude $(\%)$

Figure 8 reveals the BER performance with respect to the OSNR. This graph of figure exposes that DP-128QAM 5 spans, DP-128QAM b2b and DP-128QAM 1 span are not suitable for error free transmission at the simulated OSNR range. Besides, DP-32QAM B2B, DP-64QAM B2B gives lower BER which is compatible with our basic prediction. But DP-128QAM b2b has deviated from normal behavior, thereby not supporting acceptable BER performance. On the contrary, DP-32QAM 1 span provides very virtuous BER performance. We have observed that similar better output are obtained for DP-32QAM 1 span and DP-64QAM 1 span. Although, DP-32QAM 5 span and DP-64QAM 5 spans yields worse performance which is not acceptable for error free communications. These observations are also confirmed by the constellation point evidences shown in Table 1. Table 2 represents the comparison among related works. It validates that our design performs better in terms of OSNR than previous works. Our investigation shows the maximum OSNR of 28dB at DP-32QAM level compared to existing works in Table 2. 


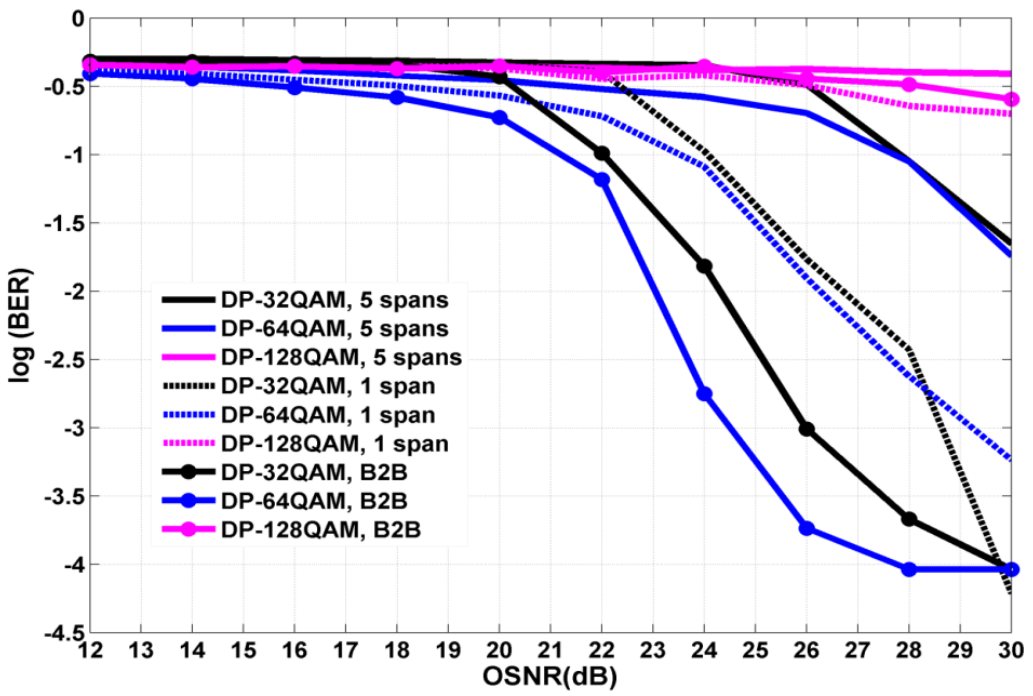

Figure 8. Performance comparison for DP- QAM levels with respect to OSNR versus log of BER

Table 1. Constellations diagrams of DP-QAM levels for COTS performance comparison

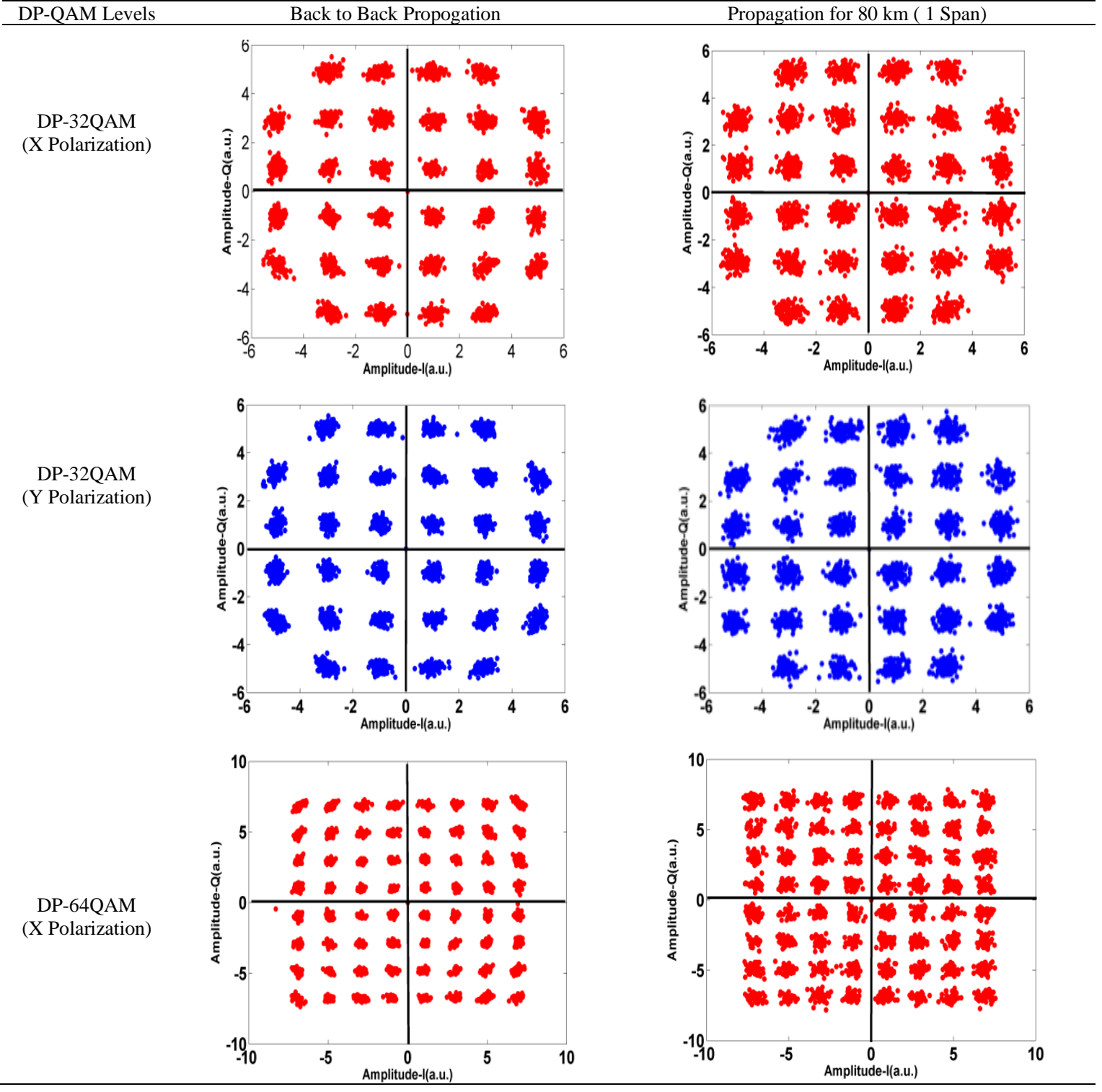


Table 1. Constellations diagrams of DP-QAM levels for COTS performance comparison (continue)

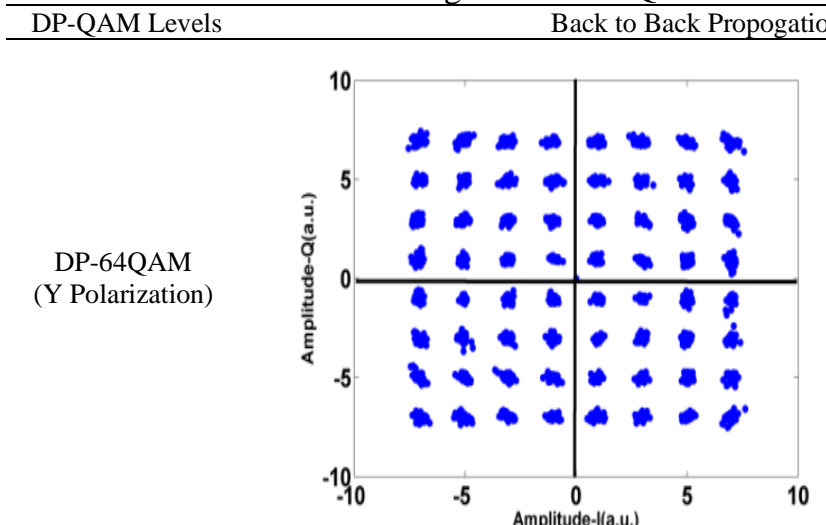
Propagation for $80 \mathrm{~km}$ ( 1 Span)

DP-128QAM

(X Polarization)
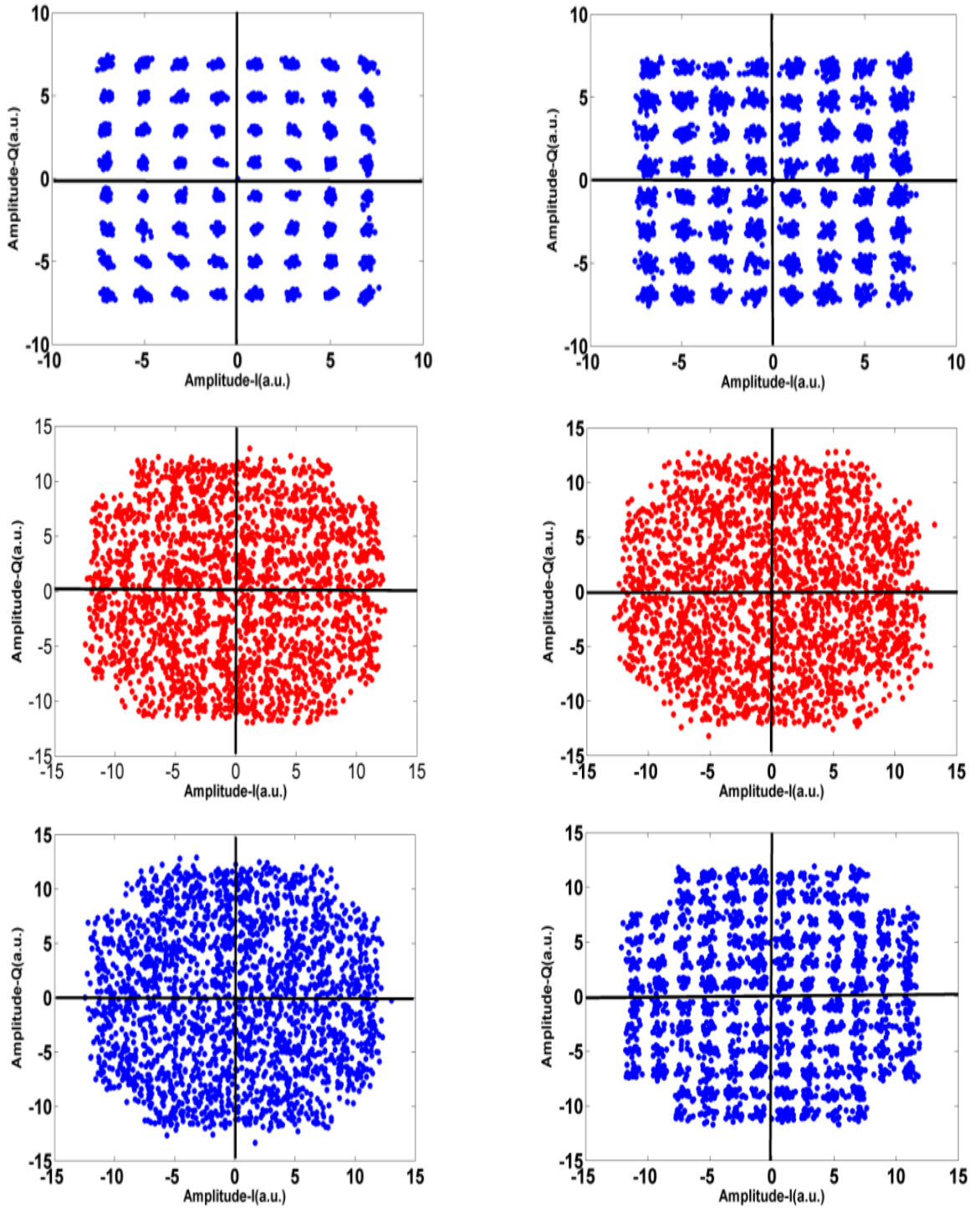

Table 2. Comparison table of our work with previous works

\begin{tabular}{|c|c|c|c|c|c|}
\hline Factors & Ref. No. [3] & Ref. No. [8] & Ref. No. [11] & Ref. No. [13] & $\begin{array}{l}\text { Current } \\
\text { Investigation }\end{array}$ \\
\hline Technology & $\begin{array}{ll}\text { Coherent } & \text { Optical } \\
\text { Systems } & \end{array}$ & $\begin{array}{l}\text { Coherent Optical } \\
\text { Systems }\end{array}$ & $\begin{array}{l}\text { Coherent Optical } \\
\text { Systems }\end{array}$ & $\begin{array}{l}\text { Coherent } \\
\text { detection }\end{array}$ & $\begin{array}{l}\text { Coherent Optical } \\
\text { Systems }\end{array}$ \\
\hline Modulation Formats & Advanced & Advanced & M-QAM & Advanced & M-QAM \\
\hline Data Rate(Gbps) & 112 & 904 & 400 & 256 & 100 \\
\hline Channel Input power(dBm) & -20 to 5 & 0 & ------ & -3 to 3 & -20 to 5 \\
\hline Wavelength/frequency & 193.1THz & $1550 \mathrm{~nm}$ & -------- & $1557.36 \mathrm{~nm}$ & $193.1 \mathrm{THz}$ \\
\hline Fiber attenuation $(\mathrm{dB} / \mathrm{km})$ & 0.2 & 0.2 & ------- & ------- & 0.2 \\
\hline Span length $(\mathrm{km})$ & 80 & 80 & -------- & 75 & 80 \\
\hline $\begin{array}{l}\text { Dispersion } \\
(\mathrm{ps} / \mathrm{nm} / \mathrm{km})\end{array}$ & 16 & 16.75 & -------- & ------- & 16 \\
\hline Polarization Type & Dual & Dual & PM & SP and Dual & Dual \\
\hline Modulation signal level & 32QAM & 128QAM & $\begin{array}{l}\text { 32QAM } \\
\text { 64QAM }\end{array}$ & $\begin{array}{l}\text { 128QAM and } \\
\text { 16QAM }\end{array}$ & 32QAM \\
\hline Amplifier & EDFA & EDFA & & EDFA & EDFA \\
\hline Amplifier Gain (dB) & 16 & 16 & -------- & ------- & 16 \\
\hline Noise Figure (dB) & 4 & 4 & -------- & --------- & 4 \\
\hline $\operatorname{OSNR}(\mathrm{dB})$ & 23.5 & 27 & 21.8 and 24.3 & 18 and 19 & 28 \\
\hline
\end{tabular}

Int J Elec \& Comp Eng, Vol. 10, No. 3, June 2020 : 2513 - 2522 


\section{CONCLUSION}

We exhibited the COTS with multiple types of DP-QAM levels. The performance of the DP-32QAM, DP-64QAM and DP-128QAM modulation formats with the same data rate (100Gb/s) and different symbol rates (10 Gsymbol/s, $8.33 \mathrm{Gsymbol} / \mathrm{s}$ and $7.142 \mathrm{Gsymbol} / \mathrm{s}$ respectively) have been compared in terms of $\mathrm{CW}$ input power. The findings based on the performance curves and constellation diagrams are in harmony with the analytical manifestation and are strong evidences to our explanation of the outputs.

This simulation work helps the calculation of EVM with respect to propagation length, input channel power for DP-QAM levels. It is interesting that for the same test bed of COTS, three DP- QAM levels performed differently. This investigation improves the optical transmission systems by minimizing the error vector magnitude (EVM). In this simulation, it is found that DP-128QAM outperforms DP-32QAM and DP-64QAM. DP-128QAM has a potentiality to rescue from the detrimental factors that arises from long haul optical fiber communications link.

\section{ACKNOWLEDGEMENTS}

The authors are thankful to University Grants Commission of Bangladesh (UGC) for sponsoring this research work under the research scheme grant, 2017.

\section{REFERENCES}

[1] Yuki Koizumi, et al., "1024 QAM (60 Gbit/s) single carrier coherent optical transmission over $150 \mathrm{~km}$," Optics Express, vol. 20, no. 11, May 2012.

[2] Xiaosheng Xiao, et al., "Influence of ASE noise on the signal OSNR and error vector magnitude in coherent optical communications," Optoelectronics Global Conference, Aug. 2015.

[3] Monika Mehra, et al., "Performance Analysis of Coherent Optical Communication System for Higher order Dual Polarization Modulation Formats," Optik- International Journal for Light and Electron Optics, vol. 135, pp. 174-179, Apr. 2017.

[4] Peter J. Winzer, "High-Spectral-Efficiency Optical Modulation Formats," Journal of Lightwave Technology, vol. 30, no. 24, pp. 3824-3835, 2012.

[5] Huaqiang Qin, et al., "Modeling of the Impacts of Nonlinear Propagation on EVM for Digital Coherent Receivers," 16th International Conference on Optical Communications and Networks (ICOCN), Aug. 2017.

[6] Z. Dong, et al., "OSNR monitoring for QPSK and 16-QAM systems in presence of fiber nonlinearities for digital coherent receivers," Optics express, vol. 20, pp. 19520-19534, 2012.

[7] A. Carena, et al., "Statistical characterization of PM-QPSK signals after propagation in uncompensated fiber links," in Proc. ECOC, 2010.

[8] Guang Li, et al., "A Pulse Shaping Based Optical Transmission System of 128QAM for DWDM with N $\times 904$ Gbps,” Applied Sciences, vol. 9, no. 5, pp. 988, Mar. 2019.

[9] Seiji Okamoto, et al., "512 QAM (54 Gbit/s) coherent optical transmission over $150 \mathrm{~km}$ with an optical bandwidth of $4.1 \mathrm{GHz}, " 36^{\text {th }}$ European Conference and Exhibition on Optical Communication (ECOC), Sep. 2010.

[10] Júlio César Medeiros Diniz, et al., "Optimization of DP-M-QAM Transmitter Using Cooperative Coevolutionary Genetic Algorithm," Journal of Lightwave Technology, vol. 36, no. 12, Jun. 2018.

[11] E. Lach, et al., "Modulation formats for $100 \mathrm{G}$ and beyond," Optical Fiber Technology, vol. 17, no. 5, pp. 377-386, 2011.

[12] B. Szafraniec, et al., "Performance monitoring and measurement techniques for coherent optical systems," Journal of Lightwave Technology, vol. 31, pp. 648-663, Feb. 2013.

[13] A. S. Kashi, et al., "Information Rates for the SP 128-QAM and DP 16-QAM Modulation Formats," European Conference on Optical Communication (ECOC), Oct. 2015.

[14] L. Alberto Campos, et al., "Proactive Network Maintenance Evolution to the Optical Domain in Coherent Optics," Advancing Technology's Agenda, Atlanta, GA, Oct. 2018.

[15] Martin Hudli cka, et al., "BER Estimation from EVM for QPSK and16-QAM Coherent Optical Systems," IEEE 6" International Conference on Photonics (ICP), Mar. 2016.

[16] Rene Schmogrow, et al., "Error Vector Magnitude as a Performance Measure for Advanced Modulation Formats," IEEE Photonics Technology Letters, vol. 24, pp. 61-63, Jan. 2012.

[17] I. Fatadin, "Estimation of BER from Error Vector Magnitude for Optical Coherent Systems," Photonics, vol. 3, no. 2, pp. 21, 2016.

[18] Maoliu Lin, et al., "EVM Simulation and its Comparison with BER for Different Types of Modulation," TENCON, Nov. 2007.

[19] Qinghua Yu, et al., "Research on Evaluation of BER in Communication system," 15 ${ }^{\text {th }}$ International Conference on Optical Communications and Networks, Sep. 2016.

[20] A. Georgiadis, et al., "Evaluation of error vector magnitude due to combined IQ imbalances and phase noise," IET Circuits, Devices \& Systems, vol. 8, no. 6, pp. 421-426, 2014. 
[21] Ruijiao Zhang, et al., "Full-duplex fiber-wireless link for alternative wired and 40-GHz band wireless access based on differential quaternary phase-shift optical single sideband millimeter-wave signal," Optical Engineering, vol. 54, Feb. 2015.

[22] Rishad Ahmed Shafik, et al., "On the Extended Relationships among EVM, BER and SNR as Performance Metrics," ICECE, 2006

[23] Chien-Yu Lin, "Digital Nonlinear Compensation for Next-Generation Optical Communication Systems Using Advanced Modulation Formats," Ph.D dissertation, Faculty of Engineering, Friedrich-Alexander-Universität Erlangen-Nürnberg, Jan. 2014. [Online], Available: https://d-nb.info/1054331367/34.

[24] By Rene'-Jean Essiambre, et al., "Capacity Trends and Limits of Optical Communication Networks," Proceedings of the IEEE, vol. 100, no. 5, May 2012.

[25] [Online], Available: https://optiwave.com.

[26] Vipanpreet Kaur, et al., "A Study of Different Forms of Dual Polarization-Quadrature Amplitude Modulation and its Performance Analysis in Terms of Q-Factor and Distance," Journal of Optical Communications, Sep. 2018. 